\title{
Comparative genomic profiling of glandular bladder tumours
}

\section{Angela Maurer $^{1}$ - Nadina Ortiz-Bruechle ${ }^{1} \cdot$ Karolina Guricova $^{1} \cdot$ Michael Rose $^{1} \cdot$ Ronja Morsch $^{1,2} \cdot$ Stefan Garczyk $^{1}$. Robert Stöhr ${ }^{3}$ - Simone Bertz ${ }^{3}$ - Reinhard Golz ${ }^{4}$. Henning Reis ${ }^{5}$. Felix Bremmer ${ }^{6}$ - Annette Zimpfer ${ }^{7}$. Sabine Siegert ${ }^{8}$. Glen Kristiansen ${ }^{9} \cdot$ Kristina Schwamborn $^{10} \cdot$ Nikolaus Gassler $^{11} \cdot$ Ruth Knuechel $^{1}$. Nadine T. Gaisa ${ }^{1}$ (1) · for the German study group of bladder cancer}

Received: 10 December 2019 / Revised: 19 February 2020 / Accepted: 27 February 2020 / Published online: 20 March 2020

(C) The Author(s) 2020

\begin{abstract}
Primary glandular bladder tumours (bladder adenocarcinoma [BAC], urachal adenocarcinoma [UAC], urothelial carcinoma with glandular differentiation $[\mathrm{UCg}]$ ) are rare malignancies with histological resemblance to colorectal adenocarcinoma (CORAD) in the majority of this subgroup. Definite case numbers are very low, molecular data are limited and the pathogenesis remains poorly understood. Therefore, this study was designed to complement current knowledge by in depth analysis of BAC $(n=12)$, UAC $(n=13), \mathrm{UCg}(n=11)$ and non-invasive glandular lesions $(n=19)$. In $\mathrm{BAC}$, in addition to known alterations in TP53, Wnt, MAP kinase and MTOR pathway, mutations in SMAD4, ARID1A and $B R A F$ were identified. Compared to published data on muscle invasive bladder cancer (BLCA) and CORAD, UCg exhibited frequent "urothelial" like alterations while BAC and UAC were characterised by a more "colorectal" like mutational pattern. Immunohistochemically, there was no evidence of DNA mismatch repair deficiency or PD-L1 tumour cell positivity in any sample. Depending on the used antibody $0-45 \%$ of BAC, $0-30 \%$ of UCg and $0 \%$ UAC cases exhibited PD-L1 expressing tumour associated immune cells. A single BAC (9\%, 1/11) showed evidence of ARID1A protein loss, and two cases of UCg (20\%, 2/10) showed loss of SMARCA1 and PBRM1, respectively. Taken together, our data suggest at least in part involvement of similar pathways driving tumourigenesis of adenocarcinomas like BAC, UAC and CORAD independent of their tissue origin. Alterations of TERT and FBXW7 in single cases of intestinal metaplasia further point towards a possible precancerous character in line with previous reports.
\end{abstract}

Keywords Bladder adenocarcinoma $\cdot$ Urothelial carcinoma with glandular differentiation · Urachal carcinoma $\cdot$ Urothelial carcinoma $\cdot$ Molecular genetics

Electronic supplementary material The online version of this article (https://doi.org/10.1007/s00428-020-02787-8) contains supplementary material, which is available to authorized users.

Nadine T. Gaisa

ngaisa@ukaachen.de

1 Institute of Pathology, University Hospital RWTH Aachen University, Pauwelsstrasse 30, 52074 Aachen, Germany

2 Department of Urology, University Hospital RWTH Aachen University, Aachen, Germany

3 Institute of Pathology, University Hospital Erlangen, Erlangen, Germany

4 Institute of Pathology, HELIOS Clinic Wuppertal, Wuppertal, Germany

5 Institute of Pathology, University Hospital Essen, University of Duisburg-Essen, Essen, Germany
6 Institute of Pathology, University Medical Center, University of Göttingen, Göttingen, Germany

7 Institute of Pathology, University Medical Center Rostock, Rostock, Germany

8 Institute of Pathology Munich-North, Munich, Germany

9 Institute of Pathology, University Hospital Bonn, Bonn, Germany

10 Institute of Pathology, Technical University Munich, Munich, Germany

11 Institute of Legal Medicine, Section Pathology, University Hospital Jena, Jena, Germany 


\section{Introduction}

Primary adenocarcinoma of the bladder is a rare malignancy accounting for $<2 \%$ of all bladder cancers [1]. Thus, in Germany, less than 200 cases of adenocarcinoma are expected each year (about 16.400 new bladder cancer cases in 2016) [2]. Besides pure primary bladder adenocarcinoma (BAC), glandular and mucinous differentiation of bladder tumours ( $1.6 \%$ or $0.8 \%$ of invasive high-grade tumours) can be found as a sign of de-differentiation in high-grade urothelial tumours (UCg; urothelial carcinoma with glandular differentiation) [3, 4]. Additionally, urachal adenocarcinomas (UAC; tumours arising from embryonic urachal remnants) also present as glandular or mucinous adenocarcinomas. Due to their special origin and different treatment strategies, they are usually considered separately. BAC can exhibit various phenotypes: enteric/colonic, mucinous/colloid, signet-ring cell, clear cell, hepatoid, mixed and adenocarcinoma not otherwise specified (NOS; if without a specific glandular growth pattern) [5]. This phenotypical diversity turns them into diagnostically challenging tumours, since - first of all — metastatic carcinomas must be excluded [6].

So far, the pathogenesis of BAC remains poorly understood, and morphological resemblance to colorectal adenocarcinomas (CORAD) suggests potential analogies. Nextgeneration sequencing (NGS) data have improved our knowledge of genetic driver alterations in urothelial carcinomas [7] and CORAD [8], and first NGS data are now available for rare BAC $[9,10]$ and UAC [11-16]. Additionally, a few single gene sequencing reports for $\mathrm{BAC}$ and $\mathrm{UAC}$ (e.g. BRAF, EGFR, KRAS, NRAS, PIK3CA, TERT) have been published [17-21]. Due to these studies alterations in "urothelial" (e.g. $R B 1)$ as well as "colorectal" (e.g. $A P C, K R A S)$, associated genes have been identified for BAC and UAC. An involvement of MAP kinase, MTOR, Wnt and TP53 pathway in BAC [9] and UAC [13] has been described.

However, these previous studies did not comparatively analyse BAC, UCg, UAC and possible precancerous glandular lesions (cystitis glandularis [CG] and intestinal metaplasia [IM]) in parallel to reveal specific tumourigenic events and pathways for each entity.

Therefore, the aim of our study was to decipher genomic similarities and differences in glandular bladder tumours (BAC, UAC and $\mathrm{UCg}$ ) in comparison to publicly available data on muscle invasive urothelial cancers (BLCA) and CORAD using a custom NGS panel covering all exons of 20 urothelial and colorectal driver genes in order to understand tumour biology and reveal suitable (targeted) therapeutic concepts. Additionally, tumours were screened for TERT promoter mutations and analysed immunohistochemically for DNA mismatch repair (MMR) deficiency, loss of SWI/SNF complex expression and PD-L1 expression.

\section{Materials and methods}

\section{Patient samples and tissue microarray construction}

Formalin-fixed, paraffin-embedded (FFPE) archival bladder cancer specimens from ten different Institutes of Pathology in Germany were collected. Each case was carefully checked within the pathology archives/data bases and by cross-check with the referring urologists in a three-step process to verify correct classification and exclude metastatic tumours (see Supplementary Methods 1 for further information). Tumour classification was performed according to the 2017 International Union Against Cancer [22] and the 2016 World Health Organization classification of bladder tumours [5]. In total, $n=12$ BAC ( $n=9$ enteric, $n=2$ mucinous and $n=1$ mixed morphology); $n=13$ UAC ( $n=10$ mucinous and $n=3$ enteric); and $n=11 \mathrm{UCg}, n=3 \mathrm{CG}$ and $n=1 \mathrm{IM}$ were available for analysis with confirming clinical data, sufficient material for sequencing and appropriate sequencing data for successful single nucleotide variants (SNV) and copy number alteration (CNA) analysis. In addition, $n=8 \mathrm{CG}$ and $n=7$ IM samples with low material were analysed only with SNapShot ${ }^{\circledR}$ for TERT promoter mutations. Tissue microarrays were constructed as previously described [6]. Clinicopathological data of the patient cohort are shown in Table 1 and of each patient individually in Supplementary Table 1. The retrospective, anonymous study was approved by the local Ethics Committee (EK 286/11).

\section{Microdissection and DNA isolation}

For microdissection, five to 15 freshly cut serial FFPE sections $(4 \mu \mathrm{m})$ were deparaffinised and stained with $0.1 \%$ methylene blue. Using a stereo microscope, areas with tumour cells were collected manually with sterile needles. DNA isolation was performed by using QIAamp ${ }^{\mathrm{TM}}$ DNA Mini Kits (Qiagen, Hilden, Germany) according to the manufacturer's instructions.

\section{Targeted next-generation sequencing}

For NGS, a self-designed amplicon panel (TruSeq Custom Amplicon v1.5, Illumina, San Diego, CA, USA) was used covering all coding exons of 20 genes known to be frequently mutated in either BLCA or CORAD (APC, ARIDIA, BRAF, CDKN1A, CDKN2A, CTNNB1, FBXW7, FGFR3, HRAS, KDM6A, KRAS, MSH6, NRAS, PIK3CA, PTEN, RB1, SMAD4, STAG2, TP53, TSC1). Library preparation was performed according to the manufacturer's protocols, and sequencing was conducted on a MiSeq $®$ benchtop sequencer (Illumina). Raw data were processed directly on the MiSeq (MiSeq Control Software, v2.6, Real-Time Analysis software, v1.18.54). For alignment and variant calling, the SeqNext Module of the 
Table 1 Clinico-pathological data of patient cohort

\begin{tabular}{|c|c|c|c|}
\hline & $\begin{array}{l}\text { Bladder } \\
\text { adenocarcinoma } \\
(n=12)\end{array}$ & $\begin{array}{l}\text { Urachal } \\
\text { adenocarcinoma } \\
(n=13)\end{array}$ & $\begin{array}{l}\text { Urothelial carcinoma } \\
\text { with glandular } \\
\text { differentiation } \\
(n=11)\end{array}$ \\
\hline \multicolumn{4}{|c|}{ Patient age (years) } \\
\hline $30-49$ & 1 & 7 & 2 \\
\hline $50-69$ & 4 & 5 & 3 \\
\hline $70-89$ & 7 & 1 & 6 \\
\hline \multicolumn{4}{|l|}{ Gender } \\
\hline Female & 3 & 6 & 3 \\
\hline Male & 9 & 7 & 8 \\
\hline \multicolumn{4}{|c|}{ Tumour stage } \\
\hline pT1 & 6 & - & 4 \\
\hline pT2 & 2 & - & 3 \\
\hline pT3 & 2 & - & 4 \\
\hline $\mathrm{Tx}$ & 2 & 2 & 0 \\
\hline TIIIA & - & 6 & - \\
\hline TIIIB & - & 4 & - \\
\hline TIIIC & - & 1 & - \\
\hline \multicolumn{4}{|c|}{ Tumour grade } \\
\hline G1 & 0 & 1 & 0 \\
\hline $\mathrm{G} 2$ & 10 & 10 & 2 \\
\hline G3 & 2 & 2 & 9 \\
\hline \multicolumn{4}{|c|}{ Nodal status } \\
\hline No & 1 & 8 & 1 \\
\hline N1 & 0 & 0 & 2 \\
\hline $\mathrm{Nx}$ & 11 & 5 & 8 \\
\hline \multicolumn{4}{|l|}{ Subtype } \\
\hline Enteric & 9 & 3 & - \\
\hline Mucinous & 2 & 10 & - \\
\hline Mixed & 1 & 0 & - \\
\hline
\end{tabular}

Sequence Pilot software (version 4.4.0, JSI medical systems $\mathrm{GmbH}$, Ettenheim, Germany) was utilized. All nonsynonymous variants with a frequency of $10 \%$ and a coverage of at least $200 \times$ were considered for further analysis. To exclude potential germline variants, variants with an allele frequency $>$ $1 \%$ in public population databases (gnomAD, [23]) were removed prior to manual review of the remaining variants. Additionally, all oncogene hotspots (RAS: Codon 12, 13, 59, 61, 117, 146; CTNNB1: Codon 33-45, BRAF: Codon 600, PIK3CA: Codon 545, 1047, FGFR3: 11 activating mutations) were examined for sufficient coverage, and hotspot variants with a frequency of $>5 \%$ were added to the variant list.

High-level CNAs were identified from amplicon coverage data with a recently developed algorithm, based on the efficiency of PCR exponential growth of single amplicons in all measured samples (ACopy, [24]). For visualisation of variants, oncoprints were created with OncoPrinter on http://cbioportal.org [25, 26].
SNaPshot ${ }^{\circledR}$ analysis for TERT and FGFR3 mutations

SNapShot ${ }^{\circledR}$ Multiplex System assay (Applied Biosystems, Foster City, USA) was used to simultaneously screen for 11 known activating FGFR3 point mutations (R248C, S249C, G372C, S373C, Y375C, G382R, A393E, K652E, K652M, $\mathrm{K} 652 \mathrm{Q}$ and $\mathrm{K} 652 \mathrm{~T}$, [27]) and for TERT promoter mutations at positions -124 (C228T) and -146 (C250T) [28, 29].

\section{Immunohistochemical analysis of DNA mismatch repair proteins, SWI/SNF complex and PD-L1}

TMAs were stained for DNA mismatch repair proteins (MLH1, MSH2, MSH6, PMS2), programmed death-ligand 1 (PD-L1) and SWI/SNF complex components (SMARCB1, SMARCA2, SMARCA4, PBRM1, ARID1A) to assess protein expression. A detailed description of the utilized staining methods, antibodies and scoring systems are found in Supplementary Methods 2-4.

\section{Results}

\section{Genomic alterations in glandular bladder tumours}

DNA of 36 glandular bladder tumours (12 BAC, 13 UAC and $11 \mathrm{UCg}$ ) was successfully sequenced and analysed for SNVs and CNAs. BAC mainly exhibited an enteric type $(9 / 12)$ while most UAC showed a mucinous histology (10/13). Clinicopathological data of the patient cohort are listed in Table 1 (for more detailed data see Supplementary Table 1). Since all oncogenic hotspots except for FGFR3 were sufficiently covered, 11 activating $F G F R 3$ mutations were additionally sequenced with $S N a P s h o t \circledast$ analysis. All detected presumably somatic alterations for BAC, $\mathrm{UAC}$ and $\mathrm{UCg}$ are summarised in Fig. 1. Only one of the analysed samples (UAC, mucinous type) showed no alteration. All other samples harboured between 1 and 9 different changes (all identified SNVs and CNAs are listed in Supplementary Tables 2 and 3). Most frequent alterations in all three subgroups were SNV and CNA of TP53, ARID1A, RB1, KRAS and PIK3CA (Fig. 1). Additionally, SMAD4 was altered in BAC $(33 \%, 4 / 12)$ and UAC $(23 \%, 3 / 13)$, but not in any of the UCg samples. On the other hand, TERT promoter mutations were present in $64 \%(7 / 11)$ of UCg cases but only in two $(17 \%, 2 / 12)$ BAC cases (both enteric type) and no UAC sample (0/13). All detected TERT mutations were located at position -124 (C228T). Due to the low number of analysed cases, a correlation of identified alterations with either mucinous or enteric morphology was not feasible. We detected two mutations of CTNNB1 (1/12 BAC; $1 / 13$ UAC) and six mutations of $A P C$ (3/12 BAC; 2/13 UAC; $1 / 11 \mathrm{UCg}$ ); however, CTNNB1 mutations were not common activation hotspot mutations and no nuclear $\beta$ - 


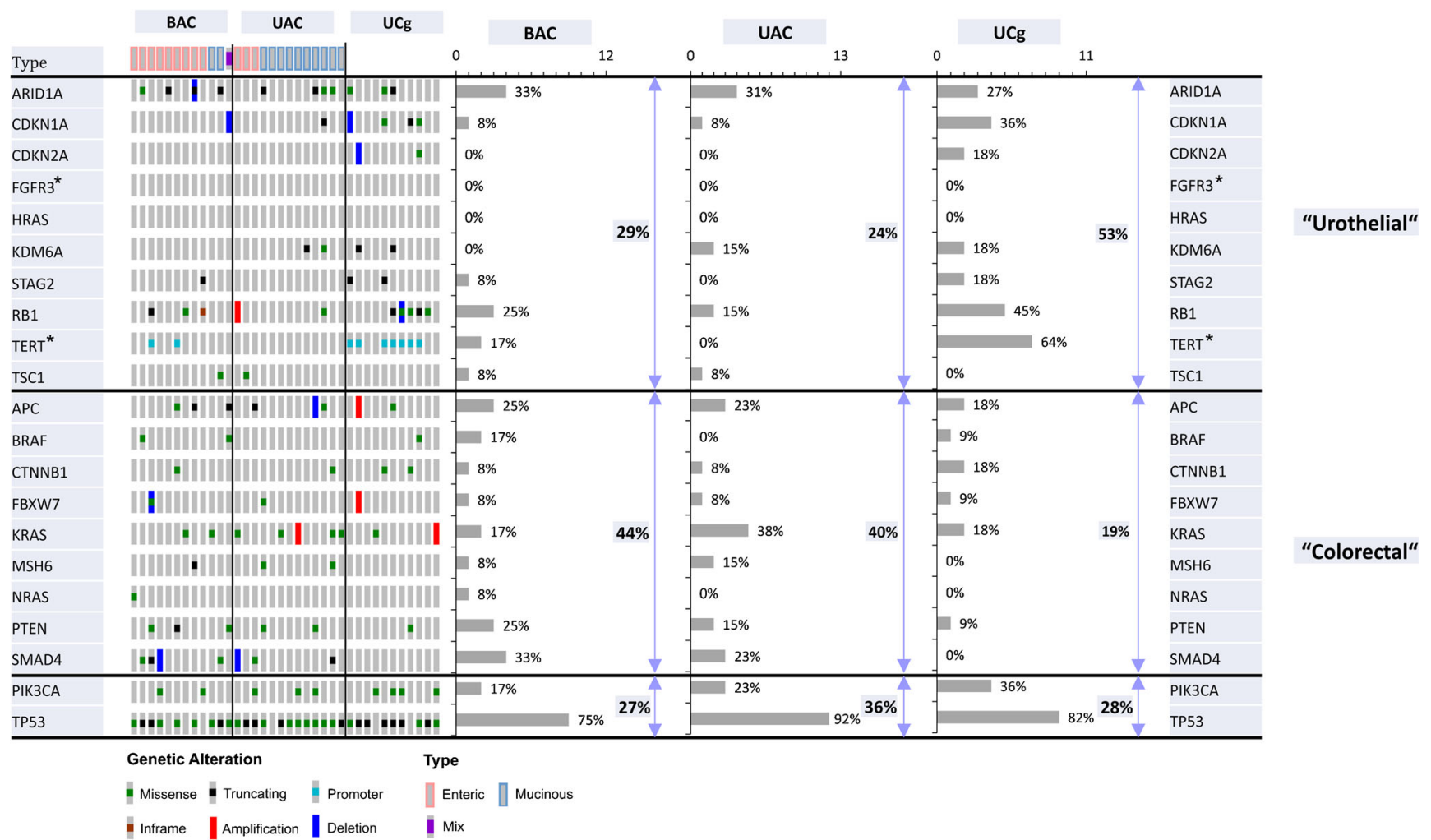

Fig. 1 Genomic alterations in glandular bladder tumours. Nonsynonymous variants (missense, truncating, inframe and promoter mutations) and CNA (amplifications and deletions) of 21 genes with mutation frequencies for each gene in each subgroup are shown (*only hotspots

catenin staining was detected in subsequent immunohistochemistry (see Table 2).

Next, analysed genes were categorised in three subgroups, i.e. an" urothelial" group with ten genes frequently altered in BLCA, a colorectal group with nine genes known to be affected in CORAD and a third group with only two genes (TP53 and PIK3CA) which are both commonly mutated in both tumour entities. UCg showed higher frequencies for alterations in BLCA associated urothelial genes (e.g. TERT, RB1, STAG2, KDM6A, CDKN1A, CDKN2A, ARID1A) while BAC and UAC exhibited genomic alterations in colorectal genes (e.g. $K R A S, S M A D 4, P T E N, A P C)$ as well as in urothelial genes (e.g. ARID1A, RB1). These results can be quantified through calculation of cumulative frequencies for alterations of each of the three groups for BAC, UAC and UCg (Fig. 1) confirming a high participation of urothelial genes in UCg genesis (53\%) and an involvement of both urothelial and colorectal genes in BAC (29\% vs. $44 \%)$ and UAC (24\% vs. $40 \%)$ development. Additionally, we determined such frequencies for BLCA and CORAD utilising publicly available SNV and CNA data from The Cancer Genome Atlas Research Network (TCGA) $(n=$ 406 BLCA, $n=526$ CORAD, accessed through http:// cbioportal.org, [30]). The individual alteration frequencies for BLCA and CORAD for all 21 genes are shown in Supplementary Figure 1. Comparison of these cumulative analysed with $S N a P s h o t \circledR)$. Overall, 36 glandular bladder tumours were analysed ( $n=12 \mathrm{BAC}, n=13 \mathrm{UAC}$ and $n=11 \mathrm{UCg}$ ). Additionally, cumulative frequencies for alterations of "urothelial" or "colorectal" associated genes are depicted for each subgroup

frequencies for glandular bladder tumours with BLCA and CORAD (Fig. 2) visualises the similarities between UCg and BLCA confirming the above identified urothelial mutational pattern of UCg while proposing a distinct genetic subgroup for BAC and UAC involving urothelial and colorectal aspects.

\section{DNA mismatch repair enzyme expression and immunohistochemical evaluation of the SNF/SWF complex activity in glandular bladder tumours}

Microsatellite instability indicated by DNA mismatch repair enzyme deficiency is well known in CORAD and less frequent in BLCA. Neither one of the analysed BAC (0/12), UAC (0/11) nor UCg (0/9) cases showed a loss of MLH1/PMS2 or MSH2/ MSH6 expression (Supplementary Table 3).

By analysing the expression of five subunits of the SWI/ SNF complex (INI1/SMARCB1, SMARCA2, SMARCA4, ARID1A, PBRM1), we further explored the relevance of alterations in chromatin remodelling in glandular differentiated tumours. One BAC sample $(9 \%, 1 / 11)$ exhibited loss of ARID1A expression (Fig. 3b) associated with a truncating ARIDIA mutation and additional loss of the non-mutated allele in the tumour tissue (Fig. $3 \mathrm{c}$ and d). Two UCg samples $(20 \%, 2 / 10)$ showed loss of SMARCA1 and PBRM1 
Table $2 \quad B$-Catenin protein expression and $A P C$ and $C T N N B 1$ mutations

\begin{tabular}{|c|c|c|c|}
\hline Sample & $\begin{array}{l}\text { ß-Catenin } \\
\text { staining (nucleus) }\end{array}$ & $\begin{array}{l}A P C \\
\text { mutations }\end{array}$ & $\begin{array}{l}C T N N B 1 \\
\text { mutations }\end{array}$ \\
\hline AE-1 & na & & \\
\hline AE-2 & Negative & & \\
\hline AE-3 & Negative & & \\
\hline AE-4 & Negative & & \\
\hline AE-5 & Negative & & \\
\hline AE-6 & Negative & $22 \%$ G502E & $24 \% \mathrm{E} 53 \mathrm{~K}$ \\
\hline AE-7 & Negative & & \\
\hline AE-8 & Negative & $86 \%$ E1573* & \\
\hline AE-9 & Negative & & \\
\hline AM-1 & Negative & & \\
\hline AM-2 & Negative & & \\
\hline AEM-1 & Negative & $38 \% \mathrm{~S} 1465 \mathrm{fs}$ & \\
\hline UM-1 & Negative & & \\
\hline UM-2 & Negative & & \\
\hline UM-3 & Positive & & \\
\hline UM-4 & Negative & & \\
\hline UM-5 & Negative & & \\
\hline UM-6 & Negative & & \\
\hline UM-7 & Negative & & \\
\hline UM-8 & Negative & $28 \%$ M485I & \\
\hline UM-9 & Negative & & $28 \% \mathrm{~W} 383 \mathrm{G}$ \\
\hline UM-10 & Negative & & \\
\hline UE-1 & Negative & & \\
\hline UE-2 & Negative & & \\
\hline UE-3 & Negative & $86 \%$ K1199* & \\
\hline UCg-1 & na & & \\
\hline $\mathrm{UCg}-2$ & Negative & & \\
\hline UCg-3 & Negative & & \\
\hline UCg-4 & Negative & & \\
\hline $\mathrm{UCg}-5$ & Negative & & \\
\hline UCg-6 & Negative & $66 \%$ V2630I & \\
\hline UCg-7 & Negative & & \\
\hline $\mathrm{UCg}-8$ & Negative & & \\
\hline UCg-9 & Negative & & \\
\hline UCg-10 & Negative & & \\
\hline UCg-11 & Negative & & \\
\hline
\end{tabular}

na not available

respectively, while for two evaluable UAC, no evidence of expression loss of any of the tested markers was detected (Supplementary Table 3).

\section{PD-L1 expression in glandular bladder tumours}

Since immune checkpoint inhibitors (ICI) have been recently approved for treatment of advanced bladder cancers with the necessity of PD-L1 "positivity" in a first-line setting, analysis of PD-L1 expression in glandular bladder cancer might reveal a treatment option for these rare subtypes. Due to the known heterogeneous performance of currently available anti-PD-L1 antibodies [31], all available samples (12 BAC, 3 UAC and 10 $\mathrm{UCg}$ ) were stained with four different anti-PD-L1 antibody clones (28-8, SP142, SP263, 22C3). Overall, no tumour cell staining (defined as TPS $\geq 1$ ) was observed and none of the three tested UAC showed an immune cell (IC) staining. Depending on the used antibody in $0-45 \%$ BAC and $0-30 \%$ UCg cases, PD-L1-expressing immune cells were detected (BAC: 3/12 [28-8], 0/12 [SP142], 5/11 [SP263], 3/10 [22C3], UCg: $2 / 10$ [28-8], 0/10 [SP142], 3/10 [SP263], 1/9 [22C3]) with up to three BAC (25\%) and three UCg (30\%) cases exhibiting an IC-Score above the current threshold for 1st-line atezolizumab therapy in metastatic bladder cancer (IC-Score $\geq 2$; Supplementary Figure $2 \mathrm{c}$ and d). Additionally, with obtained CPS (combined positivity score), none of the BAC cases was eligible for 1st-line pembrolizumab therapy while two UCg cases (20\%) with an CPS $\geq 10$ could be considered (Supplementary Figure 2 and b). A detailed list of all PD-L1 results (TPS, IC-Score and CPS) for all tested samples and antibodies can be found in Supplementary Table 3.

\section{Genomic alterations in glandular precancerous lesions}

To gain further insights into the development of BAC, we sequenced potential precancerous glandular bladder lesions. Three cases with CG and only one sample with IM were suitable for SNV and CNA analysis with NGS, while the residual cases $(n=$ 15) were only sufficient for TERT-SNapShot ${ }^{\circledR}$ analysis (clinicopathological data Supplementary Table 1). Interestingly, in one IM sample, a TERT promoter mutation was detectable at position -124 (C228T). All other IM and CG samples displayed TERT wildtype in $S N a p S h o t \cap$ analysis. The three sequenced CG cases showed neither oncogenic SNV nor CNA in any of the 20 genes, but in the IM sample, a FBXW7 alteration (R505G) predicting loss of function was identified (Supplementary Tables 2 and 3).

\section{Discussion}

In this study, we investigated a cohort of glandular bladderrelated cancers and non-invasive glandular lesions of the bladder (CG and IM) for genetic profiles. Overall, we assessed the total coding sequence of 20 genes by NGS and additional hotspots of FGFR3 and TERT by SNapShot ${ }^{\circledR}$ analysis, in order to compare these profiles with publicly available datasets of BLCA and CORAD. The main questions we wanted to address are the following: (i) are our findings consistent with existing limited data on BAC, UAC and UCg? (ii) are they molecularly related to BLCA or CORAD? (iii) are 


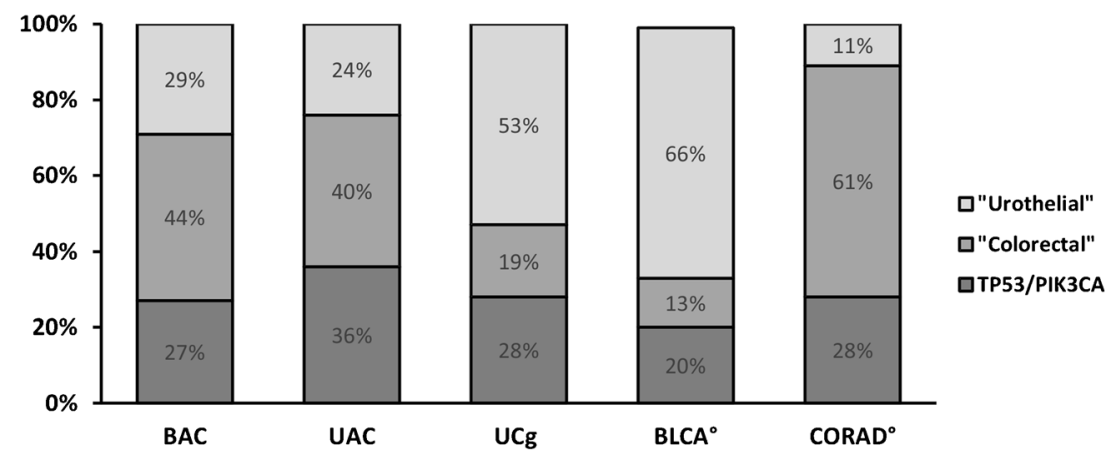

Fig. 2 Comparison of cumulative frequencies of alterations in "urothelial" or "colorectal" genes between glandular bladder tumours, BLCA and CORAD. Calculated cumulative alteration frequencies for BAC, UAC, UCg, BLCA and CORAD for ten "urothelial" (ARIDIA, CKN1A, CDKN2A, FGFR3, HRAS, KDM6A, STAG2, RB1, TERT, TSC1), nine "colorectal" (APC, BRAF, CTNNB1, FBXW7, KRAS,

there molecular events defining preinvasive glandular precancerous lesions? and (iv) are there any distinct therapeutic options for these tumour entities that might improve the current rather organ confined therapeutic regimes?

For rare BAC, currently, only one genomic profiling study (15 samples/51 genes) has been published identifying genomic alterations in genes of MAP kinase, MTOR, Wnt and TP53 pathways [9]. Another study on adenocarcinoma was recently presented but has not yet been published (14 BAC and $10 \mathrm{UAC} / 275$ genes) [10]. Roy et al. described $A P C$ and

MSH6, NRAS, PTEN, SMAD4) and two additional genes commonly altered in both (TP53, PIK3CA). ${ }^{\circ}$ Data for BLCA and CORAD alterations for the 21 genes was obtained from The Cancer Genome Atlas Research Network (TCGA) pan-cancer analysis project (accessed through http://cbioportal.org, [30])

CTNNB1 mutations and nuclear B-catenin expression (alterations of Wnt signaling) to be involved in BAC development [9]. In line with this study, we detected similar genomic alteration frequencies for $A P C$ and $C T N N B 1$, but we could not show immunohistochemical nuclear $\beta$-catenin translocation, and thus activation of the canonical Wnt pathway cannot be confirmed. We also revealed variants in the Wnt pathwayregulating gene SMAD4, which have not been described to be altered in BAC so far. SMAD4 is a tumour suppressor, and transcription factor of the TGF- $\beta$ pathway and loss of
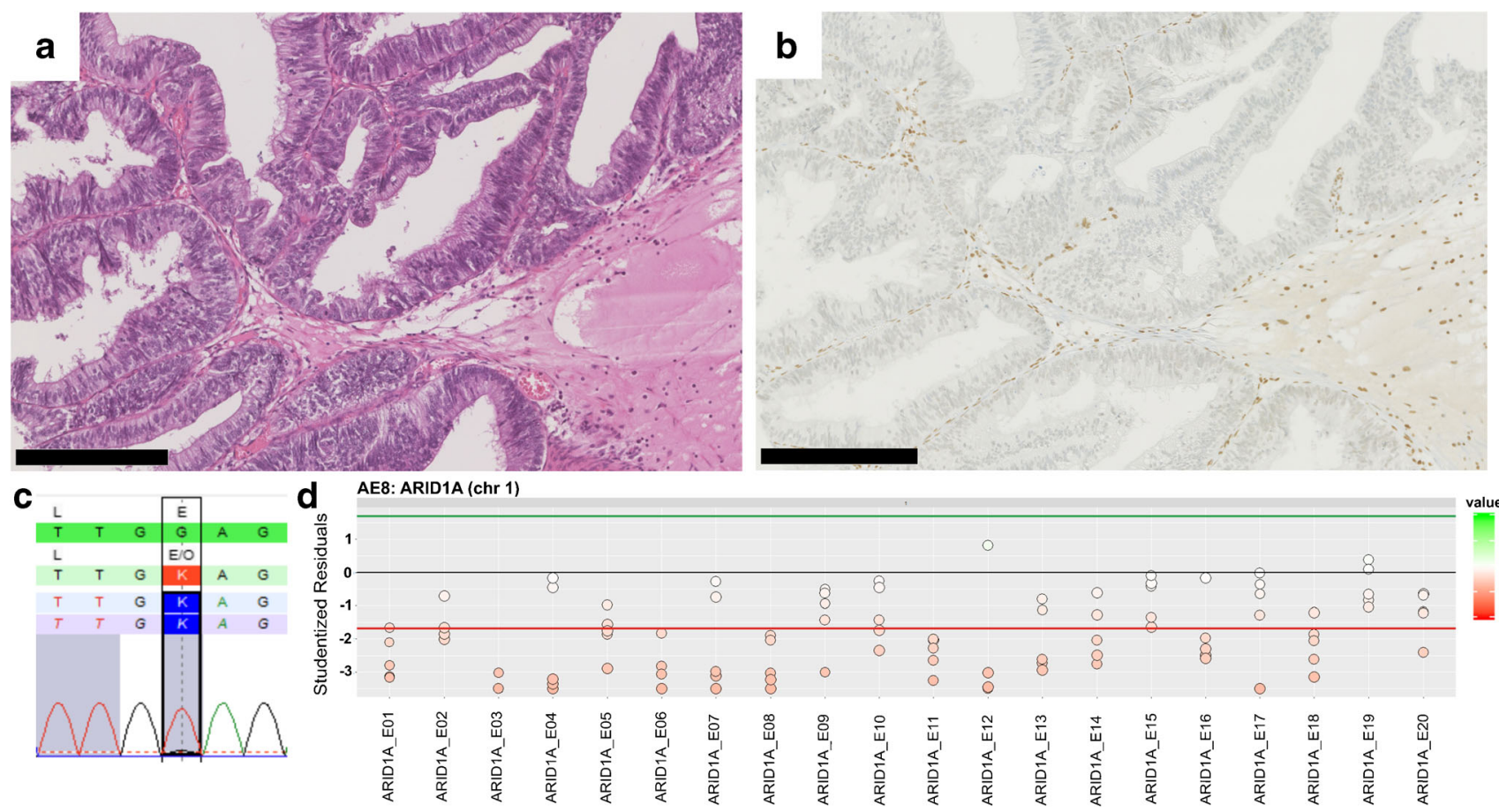

Fig. 3 Enteric BAC with loss of ARID1A. HE (a) and anti-ARID1A (b) staining of a case of BAC (enteric type) with loss of ARID1A expression in tumour tissue (black scale bar equals $250 \mu \mathrm{m}$ ). c Truncating ARIDIA mutation with an allele frequency of $88 \%$ (c.6160G $>$ T, p.Glu2054*, estimated tumour content $80 \%$ ). d Relative coverage for all exons of

ARID1A showing a deletion for sample AE-8. These results were derived through calculation of the relative coverage deviation of each amplicon from the coverage of five correlated amplicons of the same sample. In a normal diploid state with two copies, no deviation in coverage would be detected $(=0)$ 
function alterations have been shown to cause, for instance, impaired response to chemotherapy in colorectal cancer [32]. Downregulation of SMAD4 expression has been identified in pancancer transcriptome analysis to be characteristic for adenocarcinoma independent of origin [33]. However, functional SMAD4 inactivation alone is not sufficient for tumour initiation, but it is thought to promote tumour progression in conjunction with additional alterations, e.g. activating KRAS (pancreatic duct adenocarcinoma) or inactivating $A P C$ alterations (colorectal cancer) [34]. TP53 was the most frequently altered gene in the study of Roy et al. and ours, and alterations of $F B X W 7$ (no hotspot variants but cases with loss of function through either mutation or deletion detected) were similar [9]. Previous single gene analyses already identified KRAS mutations in BAC [17], which were also present in our cohort $(n=$ 2). Roy et al. reported PIK3CA mutations as a potential druggable target in BAC [9], which we also confirmed in two samples. Furthermore, we identified two cases with $B R A F$ mutations of which one (sample AEM-1) exhibited a hotspot $\mathrm{V} 600 \mathrm{E}$ variant. To our knowledge, $B R A F$ has not been reported to be altered in BAC before but could represent an important drug target [35]. A key observation of Roy et al. was the absence of any SNV or CNA in BAC with mucinous histology [9]; however, both analysed mucinous BAC cases in our cohort exhibited several mutations in KRAS, TP53 and ARIDIA, SMAD4, TP53, respectively. This discrepancy might be due to the low number of analysed cases in both studies (3/15 and 2/12 exhibited mucinous morphology). TERT promoter mutations were rarely detected in our study $(2 / 12)$ in accordance with previously published data $(4 / 14,0 / 10$ and $2 /$ 15 respectively). However, our samples were enteric BAC, whereas Cowan et al. detected TERT promoter mutations only in non-enteric BAC and Roy et al. in enteric and non-enteric (single-cell) BAC $[9,18]$, which are no longer considered to be BAC according to the current WHO classification [36]. In their overview of glandular bladder tumours, Taylor et al. hypothesised that $\mathrm{BAC}$ with TERT mutation might represent an urothelial subgroup [37]. In our cohort, both TERT mutated enteric BAC specimens (AE-3 and AE-6) additionally exhibited colorectal characteristics, i.e. alterations in SMAD4 and PTEN. Taken together, the current results for BAC from our study and from Roy et al. present BAC as a distinct entity exhibiting both characteristics of urothelial (e.g. TERT mutations, alterations in chromatin remodelling) and colorectal cancer (e.g. alterations in Wnt pathway) [9].

For UAC, several studies have been published which mainly focus on current therapeutic targets [11-16]. Reis et al. identified, for instance, various druggable alterations (e.g. $B R A F$ mutations, single cases of MET, ERBB2 and EGFR amplification) while exome-wide studies revealed recurrent alterations in TP53, Wnt/TGF- $\beta$ and MAP kinase pathways similar to those detected in our study including 13 UAC samples. In the exome study of Lee et al., UAC samples clustered as a distinct group between BLCA and CORAD comparing CNA profiles [11]. Analogously, our results support this notion as UAC exhibit not only urothelial but also frequent colorectal like alterations. This corroborates the hypothesis that BAC and UAC could be genetically specified as a distinct group between BLCA and CORAD with genetic similarities, although both develop from different sites (urothelium versus urachal remnants) with and without exposure to urine. So far, we are not able to answer the question why site different adenocarcinomas (BAC, UAC) seem to be genetically similar and show overlapping mutational patterns with CORAD including TP53, KRAS and SMAD4 [8], as their only similarities are the enteric/goblet cell types. Bearing in mind that SMAD4 function is thought to be a characteristic of adenocarcinomas [33], triggering tumour progression in close association with further mutational drivers such as activating $K R A S$, involvement of comparable molecular pathways driving tumourigenesis of adenocarcinomas like BAC, UAC and CORAD could be suggested independently of the tissue origin.

For UCg - to our best knowledge - there is only a single gene analysis while no genomic profiling studies have been published so far, excluding those analysing BLCA with mixed features (squamous, glandular, etc.) [38]. Vail et al. identified $72 \%$ (21/29) of UCg as TERT mutated, comparable to our study $(64 \% ; 7 / 11)[39]$. Although showing a slightly higher mutational rate in some "colorectal-like" genes (KRAS, APC, $C T N N B 1$ ) than BLCA, UCg mainly harboured frequent alterations in distinct urothelial-like genes (e.g. TERT, RB1, CDKN1A, ARID1A and KDM6A) as well as TP53 and $P I K 3 C A$. A particularly conspicuous aspect is the high level of TERT mutations in UCg which differ from UAC or BAC with only low numbers of TERT mutated cases [40].

We furthermore identified a TERT promoter mutation and a missense $F B X W 7$ variant in one of the tested glandular preinvasive lesions (IM sample). The detected $F B X W 7$ R505G mutation is located in the WD repeat domain at a recurrently altered hotspot (R505) with R505L and R505C associated with a loss of function through disruption of substrate binding [41, 42]. The tumour suppressor FBXW7 binds to proto-oncogenes mediating degradation, while dysregulation leads to chromosomal instability and tumourigenesis due to accumulation of oncoproteins [43]. In line with previous analysis of TERT promoter mutations in glandular bladder tumours including 25 benign glandular lesions of the bladder (with 5 CG samples amongst Brunn nests, cystitis cystica and nephrogenic adenoma), we did not detect any TERT variants in the tested CG samples [39]. While a few previous studies also detected neoplastic changes in IM (e.g. telomere shortening and chromosomal abnormalities) suggesting IM to be a precursor of adenocarcinoma, accumulating studies showed coexistence of IM and CG with bladder cancer as well as in benign bladder specimens and no correlation between 
occurrence of IM and risk for progression to tumour [44-46]. Thus, the debate is still ongoing and further molecular analysis with larger sample numbers and clinical follow-up are needed in order to prove or disprove the precancerous nature of these lesions.

Finally, we assessed our cohort for current predictive immunohistochemical marker expression, i.e. DNA mismatch repair, SWI/SNF complexes and PD-L1. We found no deficiency in DNA mismatch repair enzymes in UCg, BAC and UAC in concordance with the described low frequency of DNA mismatch repair defects in bladder cancer [47] and recent UAC [12] and BAC data [48]. Single SWI/SNF alterations (ARID1A loss in one BAC sample; no alterations in the two analysed UAC samples; two UCg cases with loss of either SMARCA2 or PBMR1 expression) can be found predominantly in the urothelial glandular tumours, with currently no therapeutic consequences [49]. None of the glandular bladder tumours showed PD-L1 expression in tumour cells, but up to $45 \%(5 / 11)$ of BAC and $30 \%$ of UCg cases (3/10) showed PD-L1 expression in immune cells; thus, ICI might be a treatment option for a subset of advanced BAC and UCg.

In conclusion, the identified mutational patterns propose not only some molecular similarities but also differences between BAC, UAC and to a certain extent also CORAD, whereas UCg follow a urothelial (BLCA) tumourigenesis. We are aware of the limited sample numbers of these rare tumours in our study; thus, the tumours should be further investigated in larger multi-institutional cohorts especially considering future therapeutic approaches. Additionally, ICI seems to be a reasonable treatment option for a subgroup of $\mathrm{BAC}$ and $\mathrm{UCg}$, but less indicated in UAC. Moreover, infrequent molecular alterations of TERT and FBXW7 in IM suggest a possible precancerous character in line with previous rare reports.

Acknowledgements The authors thank all contributing urologists, pathologists and scientists of the German Study Group of Bladder Cancer (DFBK e.V.) and are grateful for the technical support given by laboratory staff of the Institute of Pathology RWTH Aachen University Aachen and Institute of Pathology University Hospital Erlangen.

Authors' contribution AM performed and analysed the sequencing experiments and drafted the manuscript; NOB analysed the sequencing experiments and drafted the manuscript; CG developed the CNV analysis algorithm; MR and RM analysed PD-L1 IHC staining and statistics; MR edited the manuscript; SG provided and analysed ARID1A IHC staining; RS performed and analysed FGFR and TERT SNapShot analysis; SB, RG, HR, FB, AZ, SS, GK, KS, NG and RK collected samples, data and performed confirming IHC stainings; and NTG provided reference pathology for all samples, conceived the study, analysed the data and drafted and revised the manuscript. All authors revised and approved the final version of the manuscript.

Funding information Open Access funding provided by Projekt DEAL. This project was in part funded by START funds of the Medical Faculty of RWTH Aachen University (42/13 to NTG).

\section{Compliance with ethical standards}

Conflict of interest The authors declare that they have no conflict of interest.

Ethical approval All procedures performed in studies involving human participants were in accordance with the ethical standards of the institutional research committee (local Ethics Committee (EK 286/11)) and with the 1964 Helsinki declaration and its later amendments or comparable ethical standards. This was a retrospective, anonymous study on archived tissue samples.

Open Access This article is licensed under a Creative Commons Attribution 4.0 International License, which permits use, sharing, adaptation, distribution and reproduction in any medium or format, as long as you give appropriate credit to the original author(s) and the source, provide a link to the Creative Commons licence, and indicate if changes were made. The images or other third party material in this article are included in the article's Creative Commons licence, unless indicated otherwise in a credit line to the material. If material is not included in the article's Creative Commons licence and your intended use is not permitted by statutory regulation or exceeds the permitted use, you will need to obtain permission directly from the copyright holder. To view a copy of this licence, visit http://creativecommons.org/licenses/by/4.0/.

\section{References}

1. Arslan B, Bozkurt IH, Yonguc T, Vadar E, Degirmenci T, Kozacioglu Z, Gunlosoy B, Minareci S (2015) Clinical features and outcomes of nontransitional cell carcinomas of the urinary bladder: analysis of 125 cases. Urol Ann 7:177-182. https://doi. org/10.4103/0974-7796.150533

2. Kaatsch P, Spix C, Katalinic A, Hentschel S, Lutmmann S, Stegmaier C, Caspritz S, Christ M, Ernst A, Fokerts J, Hansmann J, Klein S, Kranzhöfer K, Kunz B, Manegold K, Penzkofer A, Treml K, Weg-Remers S, Wittenberg K, Baras N, Barnes B, Bertz J, Buttmann-Schweiger, DS, Fiebig J, Franke M, Haberland J, Kraywinkel K, Wienecke A, Wolf U (2015) Harnblase. In: Robert Koch-Institut und die Gesellschaft der epidemioloigschen Krebsregister in Deutschland e.V. (ed) Krebs in Deutschland 2011/ 2012, 10th edn. Robert Koch-Insitut, Berlin, pp 106-109

3. Soave A, Schmidt S, Dahlem R, Minner S, Engel O, Kluth LA, John LM, Hansen J, Schmid M, Sauter G, Shariat SF, Fisch M, Rink M (2015) Does the extent of variant histology affect oncological outcomes in patients with urothelial carcinoma of the bladder treated with radical cystectomy? Urol Oncol 33:21.e1-21.e9. https://doi.org/10.1016/j.urolonc.2014.10.013

4. Lee YJ, Moon KC, Jeong CW, Kwak C, Kim HH, Ku JH (2014) Impact of squamous and glandular differentiation on oncologic outcomes in upper and lower tract urothelial carcinoma. PLoS One 9: e107027. https://doi.org/10.1371/journal.pone.0107027

5. Moch H, Humphrey PA, Ulbright TM, Reuter VE (2016) Adenocarcinoma. In: Moch H, Humphrey PA, Ulbright TM, Reuter VE (ed) World Health Organization classification of tumours. Pathology and genetics of tumours of the urinary system and male genital organs, $4^{\text {th }}$ edn. IARC Press, Lyon, France, pp 111-112

6. Broede A, Oll M, Maurer A, Siegert S, Stoerkel S, Golz R, Schwamborn K, Veeck J, Knuechel R, Gaisa NT for the German study group of bladder cancers (2016) Differential diagnosis of bladder versus colorectal adenocarcinoma: keratin 7- and GATA 3-positivity in nuclear ß-catenin negative glandular tumours define 
adenocarcinoma of the bladder. J Clin Pathol 69:307-312. https:// doi.org/10.1136/jclinpath-2015-203144

7. The Cancer Genome Atlas Research Network (2014) Comprehensive molecular characterization of urothelial bladder carcinoma. Nature 507:315-322. https://doi.org/10.1038/ nature 12965

8. The Cancer Genome Atlas Research Network (2012) Comprehensive molecular characterization of human colon and rectal cancer. Nature 487:330-337. https://doi.org/10.1038/nature11252

9. Roy S, Pradhan D, Ernst WL, Mercurio S, Najjar Y, Parikh R, Parwani AV, Pai RK, Dhir R, Nikiforova MN (2017) Next generation sequencing-based molecular characterization of primary urinary bladder adenocarcinoma. Mod Pathol 30:1133-1143. https:// doi.org/10.1038/modpathol.2017.33

10. Pires-Luis A, Martinek P, Filipovic J, Alaghehbandan R, Trpkov K, Comperat EM, Perez Montiel MD, Bulimbasic S, Lobo J, Henrique RM, Vanecek T, Pivovarcikova K, Michalova K, Saskova B, Michal M, Hes O (2018) USCAP 2018 abstracts. \#1048: primary adenocarcinoma of the urinary bladder: next-generation sequencing (NGS) of non-urachal enteric-type adenocarcinomas, mucinous adenocarcinomas, and colonic metaplasia/adenomas. Mod Pathol 31(suppl 2):376. https://doi.org/10.1038/modpathol.2018.10

11. Lee S, Lee J, Sim SH, Lee Y, Moon KC, Lee C, Park WY, Kim NKD, Lee SH, Lee H (2017) Comprehensive somatic genome alterations of urachal carcinoma. J Med Genet 54:572-578. https:// doi.org/10.1136/jmedgenet-2016-104390

12. Reis H, van der Vos KE, Niedworok C, Herold T, Módos O, Szendröi A, Hager T, Ingenwerth M, Vis DJ, Behrendt MA, de Jong J, van der Heijden MS, Peyronnet B, Mathieu R, Wiesweg M, Ablat J, Okon K, Tolkach Y, Keresztes D, Nagy N, Bremmer F, Gaisa NT, Chlosta P, Kriegsmann J, Kovalszky I, Timar J, Kristiansen G, Radzun HJ, Knüchel R, Schuler M, Black PC, Rübben H, Hadaschik BA, Schmid KW, van Rhijn BWG, Nyirády P, Szarvas T (2018) Pathogenic and targetable genetic alterations in 70 urachal adenocarcinomas. Int J Cancer 143: 1764-1773. https://doi.org/10.1002/ijc.31547

13. Singh H, Liu Y, Xiao X, Lin L, Kim J, van Hummelen P, Wu CL, Bass AJ, Saylor PJ (2016) Whole exome sequencing of urachal adenocarcinoma reveals recurrent NF1 mutations. Oncotarget 7: 29211-29215. https://doi.org/10.18632/oncotarget.8640

14. Kardos J, Wobker SE, Woods ME, Nielsen ME, Smith AB, Wallen EM, Pruthi RS, Hayward MC, McGinty KA, Grilley-Olson JE, Patel NM, Weck KE, Black P, Parker JS, Milowsky MI, Hayes DN, Kim WY (2017) Comprehensive molecular characterization of urachal adenocarcinoma reveals commonalities with colorectal cancer, including a hypermutable phenotype. JCO Precision Oncol 2017:1-12. https://doi.org/10.1200/PO.17.00027

15. Collazo-Lorduy A, Castillo-Martin M, Wang L, Patel V, Iyer G, Jordan E, Al-Ahmadie H, Leonard I, Oh WK, Zhu J, McBride RB, Cordon-Cardo C, Solit DB, Sfakianos JP, Galsky MD (2016) Urachal carcinoma shares genomic alterations with colorectal carcinoma and may respond to epidermal growth factor inhibition. Eur Urol 70(5):771-775. https://doi.org/10.1016/j.eururo.2016.04.037

16. Riva G, Mian C, Luchini C, Girolami I, Ghimenton C, Cima L, Novelli L, Hanspeter E, Mazzoleni G, Schwienbacher C, Pycha S, D'Elia C, Trenti E, Pycha A, Martignoni G, Hes O, Eccher A, Nesi G, Brunelli M (2019) Urachal carcinoma: from gross specimen to morphologic immunohistochemical, and molecular analysis. Virchows Arch 474(1): 13-20. https://doi.org/10.1007/s00428-018-2467-1

17. Alexander RE, Lopez-Beltran A, Montironi R, MacLennan GT, Post KM, Bilbo SA, Jones TD, Huang W, Rao Q, Sen JD, Meehan K, Cornwell A, Miravalle L, Cheng L (2012) KRAS mutation is present in a small subset of primary urinary bladder adenocarcinomas. Histopathology 61:1036-1042. https://doi.org/10. 1111/j.1365-2559.2012.04309.x
18. Cowan ML, Springer S, Nguyen D, Taheri D, Guner G, Mendoza Rodriguez MA, Wang Y, Kinde I, Del Carmen Rodriguez Pena M, CJ VB, Olson MT, Cunha I, Fujita K, Ertoy D, Kinzler K, Bivalacqua T, Papadopoulos N, Vogelstein B, Netto GJ (2016) Detection of TERT promoter mutations in primary adenocarcinoma of the urinary bladder. Hum Pathol 53:8-13. https://doi.org/10. 1016/j.humpath.2016.02.009

19. Alexander RE, Montironi R, Lopez-Beltran A, Williamson SR, Wang M, Post KM, Sen JD, Arnold AK, Zhang S, Wang X, Koch MO, Hahn NM, Masterson TA, MacLennan GT, Davidson DD, Compérat E, Cheng L (2014) EGFR alterations and EML4ALK rearrangement in primary adenocarcinoma of the urinary bladder. Mod Pathol 27:107-112. https://doi.org/10.1038/ modpathol.2013.132

20. Sirintrapun SJ, Ward M, Woo J, Cimic A (2014) High-stage urachal adenocarcinoma can be associated with microsatellite instability and KRAS mutations. Hum Pathol 45:327-330. https://doi.org/ 10.1016/j.humpath.2013.09.008

21. Modos O, Reis H, Niedworok C, Rübben H, Szendröi A, Szász MA, Tímár J, Baghy K, Kovalszky I, Golabek T, Chlosta P, Okon K, Peyronnet B, Mathieu R, Shariat SF, Hollósi P, Nyirády P, Szarvas T (2016) Mutations of KRAS, NRAS, BRAF, EGFR, and PIK3CA genes in urachal carcinoma: occurrence and prognostic significance. Oncotarget 7:39293-39301. https://doi.org/10. 18632/oncotarget.9828

22. Brierley JD, Gospodarowicz MK, Wittekind C (2017) Urinary bladder. In: Brierley JD, Gospodarowicz MK, Wittekind C (ed) TNM classification of malignant tumours, $8^{\text {th }}$ edn. WileyBlackwell in affiliation with the Union for International Cancer Control (UICC), Weinheim, pp 259-261

23. Karczewski KJ, Francioli LC, Tiao G, Cummings BB, Alfoldi J, Wang Q, Collins RL, Laricchia KM, Ganna A, Birnbaum DP, Gauthier LD, Brand H, Solomonson M, Watts NA, Rhodes D, Singer-Berk M, Seaby EG, Kosmicki JA, Walters RK, Tashman K, Farjoun Y, Banks E, Poterba T, Wang A, Seed C, Whiffin N, Chong JX, Samocha KE, Pierce-Hoffman E, Zappala Z, O’Donnell-Luria AH, Vallabh Minikel E, Weisburd B, Lek M, Ware JS, Vittal C, Armean IM, Bergelson L, Cibulskis K, Connolly KM, Covarrubias M, Donnelly S, Ferriera S, Gabriel S, Gentry J, Gupta N, Jeandet T, Kaplan D, Llanwarne C, Munshi R, Novod S, Petrillo N, Roazen D, Ruano-Rubio V, Saltzmann A, Schleicher M, Soto J, Tibbetts K, Tolonen C, Wade G, Talkowski ME, The Genome Aggregation Database Consortium, Neale BM, Daly MJ, MacArthur DG (2019) Variation across 141,456 human exomes and genomes reveals the spectrum of loss-of-function intolerance across human protein-coding genes. bioRxiv preprint first posted online Jan. 28, 2019. https://doi.org/10.1101/531210

24. Guricova K, Maurer A, Gaisa NT, Garczyk S, Knüchel-Clarke R, Dahl E, Ortiz Brüchle N (2019) Abstracts 103. Jahrestagung der Deutschen Gesellschaft für Pathologie. AG12.P.03: Ein robustes Tool zur Kopienzahlanalyse für verschiedene amplikon-basierte NGS-Panel (ACopy). Pathologe 40(S2):S196

25. Gao J, Aksoy BA, Dogrusoz U, Dresdner G, Gross B, Sumer SO, Sun Y, Jacobsen A, Sinha R, Larsson E, Cerami E, Sander C, Schultz N (2013) Integrative analysis of complex cancer genomics and clinical profiles using the cBioPortal. Sci Signal 6:11. https:// doi.org/10.1126/scisignal.2004088

26. Cerami E, Gao J, Dogrusoz U, Gross BE, Sumer SO, Aksoy BA, Jacobsen A, Byrne CJ, Heuer ML, Larsson E, Antipin Y, Reva B, Goldberg AP, Sander C, Schultz N (2012) The cBio cancer genomics portal: an open platform for exploring multidemensional cancer genomics data. Cancer Discov 2:401-404. https://doi.org/10. 1158/2159-8290.CD-12-0095

27. van Oers JM, Lurkin I, van Exsel AJ, Nijsen Y, van Rhijn BW, van der Aa MN, Zwarthoff EC (2005) A simple and fast method for the simultaneous detection of nine fibroblast growth factor receptor 3 
mutations in bladder cancer. Clin Cancer Res 11:7743-7748. https://doi.org/10.1158/1078-0432.CCR-05-1045

28. Stoehr R, Taubert H, Zinnall U, Giedl J, Gaisa NT, Burger M, Ruemmele P, Hurst CD, Knowles MA, Wullich B, Hartmann A (2015) Frequency of TERT promoter mutations in prostate cancer. Pathobiology 82:53-57. https://doi.org/10.1159/000381903

29. Hurst CD, Platt FM, Knowles MA (2014) Comprehensive mutation analysis of the TERT promoter in bladder cancer and detection of mutations in voided urine. Eur Urol 65:367-369. https://doi.org/10. 1016/j.eururo.2013.08.057

30. The Cancer Genome Atlas Research Network, Weinstein JN, Collisson EA, Mills GB, Mills Shaw KR, Ozenberger BA, Ellrott K, Shmulevich I, Sander C, Stuart JM (2013) The Cancer Genome Atlas Pan-Cancer analysis project. Nat Genet 45:1113-1120. https://doi.org/10.1038/ng.2764

31. Eckstein M, Erben P, Kriegmair MC, Worst TS, Weiß CA, Wirtz RM, Wach S, Stoehr R, Sikic D, Geppert CI, Weyerer V, Bertz S, Breyer J, Otto W, Keck B, Burger M, Taubert H, Weichert W, Wullich B, Bolenz C, Hartmann A, Erlmeier F (2019) Performance of the Food and Drug Administration/EMAapproved programmed cell death ligand-1 assays in urothelial carcinoma with emphasis on therapy stratification for first-line use of atezolizumab and pembrolizumab. Eur J Cancer 106:234-243. https://doi.org/10.1016/j.ejca.2018.11.007

32. Wassermann I, Lee LH, Ogino S, Marco MR, Wu C, Chen X, Datta J, Sadot E, Szeglin B, Guillem JG, Paty PB, Weiser MR, Nash GM, Saltz L, Barlas A, Manova-Todorova K, Uppada SPB, Elghouayel AE, Ntiamoah P, Glickman JN, Hamada T, Kosumi K, Inamura K, Chan AT, Nishihara R, Cercek A, Ganesh K, Kemeny NE, Dhawan P, Yaeger R, Sawyers CL, Garcia-Aguilar J, Giannakis M, Shia J, Smith JJ (2019) SMAD4 loss in colorectal cancer patients correlates with recurrence, loss of immune infiltrate, and chemoressistance. Clin Cancer Res 25(6):1948-1956. https://doi.org/10.1158/10780432.CCR-18-1726

33. Lin EW, Karakasheva TA, Lee DJ, Lee JS, Long Q, Bass AJ, Wong KK, Rustgi AK (2017) Comparative transcriptomes of adenocarcinomas and squamous cell carcinomas reveal molecular similarities that span classical anatomic boundaries. PLoS Genet 13(8): e1006938. https://doi.org/10.1371/journal.pgen.1006938

34. Zhao M, Mishra L, Deng CX (2018) The role of TGF-B/SMAD4 signaling in cancer (2018). Int J Biol Sci 14(2):111-123. https://doi. org $/ 10.7150 /$ ijbs. 23230

35. Tolcher AW, Peng W, Calvo E (2018) Rational approaches for combination therapy strategies targeting the MAP kinase pathway in solid tumors. Mol Cancer Ther 17(1):3-16. https://doi.org/10. 1158/1535-7163.MCT-17-0349

36. Moch H, Humphrey PA, Ulbright TM, Reuter VE (2016) Plasmacytoid urothelial carcinoma. In: Moch H, Humphrey PA, Ulbright TM, Reuter VE (ed) World Health Organization classification of tumours. Pathology and genetics of Tumours of the urinary system and male genital organs, 4th edn. IARC press, Lyon, France, pp 91-92

37. Taylor AS, Mehra R, Udager A (2008) Glandular tumors of the urachus and urinary bladder: a practical overview of a broad differential diagnosis. Arch Pathol Lab Med 142(10):1164-1176. https:// doi.org/10.5858/arpa.2018-0206-RA

38. Robertson AG, Kim J, Al-Ahmadie H, Bellmunt J, Guo G, Cherniack AD, Hinoue T, Laird PW, Hoadley KA, AKbani R, Castro MAA, Gibb EA, Kanchi RS, Gordenin DA, Shukla SA, Sanchez-Vega F, Hansel DE, Czerniak BA, Reuter VE, Su X, de Sa CB, Chagas VS, Mungall KL, Sadeghi S, Pedamallu CS, Lu Y,
Klimczak LJ, Zhang J, Choo C, Ojesina AI, Bullmann S, Leraas KM, Lichtenberg TM, Wu CJ, Schultz N, Getz G, Meyerson M, Mills GB, McConkey DJ, Research Network TCGA, Weinstein JN, Kwiatkowski DJ, Lerner SP (2017) Comprehensive molecular characterization of muscle-invasive bladder cancer. Cell 171(3): 540-556.e25. https://doi.org/10.1016/j.cell.2017.09.007

39. Vail E, Zheng X, Zhou M, Yang X, Fallon JT, Epstein JI, Zhong M (2015) Telomerase reverse transcriptase promoter mutations in glandular lesions of the urinary bladder. Ann Diagn Pathol 19(5): 301-305. https://doi.org/10.1016/j.anndiagpath.2015.06.007

40. Thiem S, Herold T, Krafft U, Bremmer F, Tolkach Y, Szász AM, Kriegsmann J, Gaisa NT, Niedworok C, Szarvas T, Reis H (2017) Telomerase reverse transcriptase (TERT) promoter mutations are rare in urachal cancer. Pathol Int 67(12):597-601. https://doi.org/ 10.1111/pin.12594

41. O'Neil J, Grim J, Strack P, Rao S, Tibbitts D, Winter C, Hardwick J, Welcker M, Meijerink JP, Pieters R, Draetta G, Sears R, Clurman BE, Look AT (2007) FBW7 mutations in leukemic cells mediate NOTCH pathway activation and resistance to $y$-secretase inhibitors. JEM 204(8):1813-1824. https://doi.org/10.1084/jem.20070876

42. Kim E, IlicN SY, Zou L, Kamburov A, Zhu C, Yang X, Lubonja R, Tran N, Nguyen C, Lawrence MS, Piccioni F, Bagul M, Doench JG, Chouinard CR, Wu X, Hogstrom L, Natoli T, Tamayo P, Horn H, Corsello SM, Lage K, Root DE, Subramanian A, Golub TR, Getz G, Boehm JS, Hahn WC (2016) Systematic functional interrogation of rare cancer variants identifies oncogenic alleles. Cancer Discov 6(7): 714-726. https://doi.org/10.1158/2159-8290.CD-16-0160

43. Welcker M, Clurman BE (2008) FBW7 ubiquitin ligase: a tumour suppressor at the crossroads of cell division, growth and differentiation. Nat Rev Cancer 8(2):83-93. https://doi.org/10.1038/nrc2290

44. Morton MJ, Zhang S, Lopez-Beltran A, MacLennan GT, Eble JN, Montironi R, Sung MT, Tan PH, Zheng S, Zhou H, Cheng L (2007) Telomere shortening and chromosomal abnormalities in intestinal metaplasia of the urinary bladder. Clin Cancer Res 13(20):6232 6236. https://doi.org/10.1158/1078-0432.CCR-07-0121

45. Smith AK, Hansel DE, Jones JS (2007) Role of cystitis cystica et glandularis and intestinal metaplasia in development of bladder carcinoma. Urology 71(5):915-918. https://doi.org/10.1016/j. urology.2007.11.079

46. Young RH, Bostwick DG (1996) Florid cystitis glandularis of intestinal type with mucin extravasation a mimic of adenocarcionoma. Am J Surg Pathol 20(12):1462-1468. https:// doi.org/10.1097/00000478-199612000-00005

47. Bonneville R, Krook MA, Kautto EA, Miya J, Wing MR, Chen HZ, Reeser JW, Yu L, Roychowdhury S (2017) Landscape of microsatellite instability across 40 cancer types. JCO Precis Oncol 2017:1-15. https://doi.org/10.1200/PO.17.00073

48. Jones D, Guan JJ, Calagua C, Hansel DE, Epstein JI, Ye H (2019) Primary adenocarcinoma of the bladder lacks mismatch repair deficiency and demonstrates PD-L1 expression in tumor-infiltrating immune cells, with implications in both diagnosis and therapeutics. Hum Pathol. https://doi.org/10.1016/j.humpath.2019.10.005

49. Morel D, Almounzi G, Soria JC, Postel-Vinay S (2017) Targeting chromatin defects in selected solid tumors based on oncogene addiction, synthetic lethality and epigenetic antagonism. Ann Oncol 28(2):254-269. https://doi.org/10.1093/annonc/mdw552

Publisher's note Springer Nature remains neutral with regard to jurisdictional claims in published maps and institutional affiliations. 